\title{
EL CONTROL DE CONSTITUCIONALIDAD EN CUBA: RECUENTO HISTÓRICO Y VALORACIONES PRELIMINARES DE LA NUEVA PROPUESTA EN LA CONSTITUCIÓN DE 2019
}

\section{The control of constitutionality in Cuba: Historical record and preliminary assessments of the new proposal in the constitution of 2019}

\author{
CARLOS MANUEL VILLABELLA ARMENGOL ${ }^{1}$ \\ Instituto Tecnológico y de Estudios Superiores de Monterrey \\ cavillabella84@gmail.com
}

Cómo citar/Citation

Villabella Armengol, C. M. (2019).

El control de constitucionalidad en Cuba: recuento histórico y valoraciones preliminares de la nueva propuesta en la Constitución de 2019.

Anuario Iberoamericano de Justicia Constitucional, 23(1), 87-110.

doi: https://doi.org/10.18042/cepc/aiic.23.03

\section{Resumen}

El control de constitucionalidad en Cuba ha marchado a contracorriente de la tendencia mundial. Durante la primera mitad del siglo xx se instaló un modelo

\footnotetext{
Especialista en Derecho Constitucional y Ciencia Política por el Centro de Estudios Constitucionales de Madrid. Máster por la Universidad de Granada. Doctor en Ciencias Jurídicas por la Universidad de La Habana. Estudios posdoctorales en la Universidad de Oviedo. Integra varias redes académicas internacionales. Ha impartido cursos en numerosas instituciones y universidades de España y Latinoamérica. Es autor o coautor de 36 obras y ha publicado 21 artículos en revistas científicas de varios países en los últimos años. Es profesor de la Escuela de Ciencias Sociales y Gobierno del TEC de Monterrey, en México, coordina el Programa de Doctorado del Centro de Ciencias Jurídicas de Puebla y es director de la Revista IUS.
} 
concentrado y no especializado en manos de la Corte Suprema, a la que se accedía mediante recurso incidental de parte afectada, acción pública plural y acción pública individual. En la segunda mitad del siglo xx se implementó un modelo concentrado y semiespecializado con el Tribunal de Garantías Constitucionales y Sociales, que funcionó como sala del Tribunal Supremo, y, además de los recursos mencionados, se regularon otras acciones procesales. Este canon de justicia constitucional constituyó una innovación para la época en la región. La Constitución socialista de 1976 desconoció estos aportes e implementó un esquema de revisión de constitucionalidad político que no operó en la práctica. La Carta Magna aprobada en 2019 supera el texto anterior, pero resulta omiso e incompleto. El artículo valora la evolución del control de constitucionalidad en Cuba auxiliándose de los métodos histórico-lógico, análisis-síntesis y exegético.

\section{Palabras clave}

Control de constitucionalidad en Cuba; constitucionalismo cubano y justicia constitucional; los modelos de control constitucional en Cuba.

\section{Abstract}

The control of constitutionality in Cuba has gone against the trend of the world. During the first half of the 20th Century, a concentrated and non-specialized model was installed in the hands of the Supreme Court, which was accessed through an incidental appeal from an affected party, plural public action and individual public action. In the second half of the 20th Century, a concentrated and semi-specialized model was implemented with the Court of Constitutional and Social Guarantees, which functioned as The Supreme Court Chamber, and in addition to the mentioned resources, other procedural actions were regulated. This Canon of Constitutional Justice was an innovation at the time in the region. The socialist Constitution of 1976 ignored these contributions and implemented a scheme of revision of political constitutionality that did not operate in the practice. The Magna Carta approved in 2019 exceeds the previous text, but it is omitted and incomplete. The article assesses the evolution of the control of constitutionality in Cuba. It is supported by a historical-logical, analysis-synthesis and exegetical methods.

\section{Keywords}

Control of constitutionality in Cuba, Cuban constitutionalism and constitutional justice, models of constitutional control in Cuba 


\section{SUMARIO}

I. SINOPSIS DE LA HISTORIA CONSTITUCIONAL CUBANA. II. EL MODELO DE CONTROL JUDICIAL DE 1901. III. EL TRIBUNAL DE GARANTÍAS CONSTITUCIONALES Y SOCIALES DE 1940. IV. EL CONTROL POLÍTICO INSTITUIDO EN 1976 Y EL NUEVO CANON DE 2019. BIBLIOGRAFÍA

\section{SINOPSIS DE LA HISTORIA CONSTITUCIONAL CUBANA}

El derecho constitucional cubano ha discurrido por tres etapas: el siglo XIx bajo el dominio colonial español, la primera mitad del siglo $\mathrm{xx}$, donde se configuró la república, y el período iniciado en 1959 con el triunfo de la revolución socialista.

En el primer momento se yuxtapusieron textos españoles y las constituciones emitidas durante la guerra de Independencia.

De las cartas magnas españolas de esa centuria, 1812, 1834, 1837, 1845, 1869 y 1876 , los documentos de 1812 y 1837 tuvieron especial efecto en la isla. La Constitución gaditana rigió en los períodos de 1812-1814 y 1820-1823. Refrendó un régimen asimilista y de igualdad, al declarar que la nación era la reunión de todos los españoles de ambos hemisferios, postura aprobada previamente en las Cortes Generales y Extraordinarias en los decretos de 15 de octubre de 1810 y 9 de febrero de 1811 (Portuondo, 2008: I, 101). Difundió las ideas liberales y propició el debate al legitimar la libertad de prensa y palabra, lo que facilitó la politización de las reflexiones sobre los temas nacionales y la alineación de los diferentes estamentos sociales en torno a ellos: «La mayor repercusión en Cuba radica en lo ideológico, en la siembra hecha en la cultura política de la colonia. Catalizó un adelanto significativo en la conformación de nuestra nacionalidad, al propiciar el debate de ideas y visiones y los necesarios procesos de tipificación y diferenciación de identidades» (Suárez, 2011: 48).

La Constitución de 1837 marcó un viraje en el tratamiento de las colonias al legitimar un régimen de excepcionalidad. Obedeció al consenso entre progresistas y moderados de alejarse de la normativa de 1812, concibiéndose un documento que fue "doctrinalmente simbiótico, sincrético y transaccional» (Varela, 1983-1984: 95). El trato diferenciador y excluyente se patentizó, primero, al no permitirse que los diputados electos tomaran posesión de sus 
cargos, y, luego, en el artículo adicional segundo, que expresó que las provincias de ultramar serían gobernadas por leyes especiales.

Esa política diferenciadora se ratificó por las constituciones de 1869 y 1876, y se concretó, finalmente, con la Constitución Autonómica de 1897 para Cuba y Puerto Rico promulgada por Real Decreto de 25 de noviembre de 1897, que estuvo vigente del primero de mayo de 1898 hasta el primero de enero de 1899. El modelo de gobierno descentralizador que implementó constituía una aspiración desde inicios del siglo xIx. La metrópoli lo había enarbolado oportunistamente en momentos de crisis del sistema colonial, aunque nunca llegó a concretar cambios reales en el régimen centralista (Bizcarrondo y Elorza, 2001). Por ello, la ley mencionada significó una solución tardía, desesperada e inútil, de resolver el "problema cubano». Como expresa Franco Pérez:

La descentralización colonial fue enfocada de forma diferente desde un lado y otro del Atlántico. Desde la Isla el proyecto descentralizador fue diseñado como estrategia [...] para que España otorgase potestad legislativa [a fin] de que los cubanos pudieran construir un espacio político propio. Desde la península la descentralización colonial siempre fue vista con reticencia [...] y cuando se utilizó se hizo como [...] estrategia de contención [...] del nacionalismo independentista (2002: 318).

El derecho español decimonónico mencionado respondió a un período de transición en el que se asientan las bases de la España contemporánea, una etapa inestable políticamente, en la que progresaron un constitucionalismo transaccional y un Estado que no definió su fisonomía (Varela, 2011: 13-25). En ese contexto, la relación entre España y Cuba fue un diálogo «entre sordos y ciegos» (Portuondo, 2008: 75), y los liberales españoles no concretaron una solución política al tema colonial: «Fue una historia de paternalismo y mezquindad, de tira y afloja, de ensayos y experimentos, convertida Cuba en laboratorio institucional y permanente problema para el que no se acabó de encontrarse solución [...]» (Alonso, 2002: 59-60).

En el siglo XIX se encuentran también los textos promulgados durante la guerra de Independencia contra España, identificados con el nombre del territorio en donde se redactaron: Guáimaro, 1869; Baraguá, 1878; Jimaguayú, 1895, y La Yaya, 1897.

La Constitución de Guáimaro fue un documento breve, sin subdivisiones, concebido como provisional para que rigiera durante la guerra. Trasciende porque institucionalizó esta y aseguró la unidad política (Villabella y Matilla, 2009). El texto de Baraguá fue expresión de la protesta del mismo nombre que repudió el Pacto del Zanjón que se firmó con España para finalizar la 
beligerancia. En puridad, fue un estatuto simbólico que expuso la voluntad de continuar luchando hasta obtener la independencia (Hernández, 1960: 30). El documento de Jimguayú fue igualmente un texto breve que declaró la conformación de la isla como Estado independiente, bajo el nombre de República de Cuba. La Carta Magna de La Yaya fue la más acabada en cuanto a forma (estructurada en títulos y secciones) y contenido (reguló la ciudadanía, el territorio y contó con partes orgánica y dogmática).

Estas leyes fundaron el derecho constitucional patrio y expusieron el decurso formativo de la nacionalidad cubana, en tanto la guerra de la que emanaron fue «la matriz de la nación» (Vitier, 1990: 100). Fueron gestadas para legitimar e institucionalizar la gesta liberadora, acogieron los principios liberales y entre ellas hubo continuidad constituyente y técnica. Se destacan las constituciones de Guáimaro y La Yaya por su simbolismo y contornar cánones políticos diferentes.

En el segundo período constitucional referido se emitieron seis leyes fundamentales: la Constitución de 1901; el texto de 1928 que se gestó como enmienda y culminó emitiéndose como un documento nuevo, cuestión por la cual se consideró ilegítimo (Álvarez, 1953: 11; Gutiérrez, 1938: XXIII); el Estatuto para el Gobierno Provisional de 1933; la Ley Constitucional del Gobierno Provisional de 1934; la Ley Constitucional de 1935; la Constitución de 1940, y el Estatuto Constitucional de 1952.

La ley suprema de 1901 promulgada por la Orden Militar número 181 el 20 de mayo de 1902 resultó de una constituyente que, además de elaborar el documento constitucional, definió el marco jurídico de las relaciones con Estados Unidos, tema que resultó el más tenso de la asamblea porque los delegados fueron presionados hasta lograr que la carta se promulgara con el addendum de la «Enmienda Platt ${ }^{2} »$. Este instrumento cercenó la independencia y soberanía al imponer condiciones para las relaciones exteriores de Cuba, excluir la Isla de Pinos del territorio nacional, estipular la entrega de tierras para la construcción de carboneras o estaciones navales y legitimar el derecho de intervención de Estados Unidos (Roig, 1961). El texto constitucional recogió los postulados del liberalismo decimonónico y estuvo influenciado por la Carta Magna norteamericana en varios aspectos de su contenido (Ferrara, 1945: 29).

A partir de la década del treinta sobrevino un período de inestabilidad político-institucional en el que se sucedieron varios presidentes de facto (algunos duraron solo días) y diversas leyes constitucionales que reprodujeron

2 Enmienda propuesta por el senador Orville Hitchcock Platt a la Ley de Gastos del Ejército norteamericano en 1901. 
el canon de la ley fundamental anterior. El Estatuto para el Gobierno Provisional fue un texto de siete artículos que establecieron principios generales del gobierno, estuvo vigente de septiembre de 1933 a febrero del siguiente año. La Ley Constitucional de febrero de 1934 reprodujo el texto de inicios de siglo, modificando el mecanismo orgánico de poder e introduciendo algunas novedades en los derechos; rigió hasta marzo de 1935 y en ese lapso tuvo trece reformas. La Ley Constitucional de 1935 retomó también el texto de 1901, añadiendo alrededor de doce artículos y treinta disposiciones transitorias que ordenaron el régimen de gobierno que fungiría provisionalmente hasta las elecciones generales que se producirían al año siguiente.

La Carta Magna de 1940 mutó el canon introducido por el texto de 1901. Fue un documento extenso, de alta proyección social, progresista e innovador. Su vigencia se vio interrumpida por el golpe de Estado de marzo de 1952, que fue legitimado por el Estatuto Constitucional de abril de ese año. En octubre de 1953 fue restaurada.

La etapa republicana descrita sucintamente se caracterizó por la inestabilidad política, las rupturas democráticas ${ }^{3}$ y la fragilidad constitucional. Los documentos que la integraron expresaron la conformación y evolución del Estado-nación en condiciones de protectorado de Estados Unidos, país que ejerció permanente injerencia en la política local a través de su embajada.

Sobresalen las leyes supremas de 1901 y 1940 porque emanaron de procesos constituyentes y refrendaron paradigmas diferentes, convirtiéndose en cánones sobre los que se desplegaron sendos ciclos constitucionales. La Constitución de 1901 fungió como basamento jurídico del Estado de derecho que nació con la culminación de la guerra y respondió al modelo liberal de constitución. La Constitución de 1940 fue precursora del constitucionalismo social, abarcadora en contenidos, principista, programática, novedosa, y evidenció la quiebra del formato constitucional consagrado a inicios de siglo.

La tercera etapa del constitucionalismo cubano se integra por tres textos: la Ley Fundamental de 1959, la Constitución de 1976 y la Constitución de 2019.

La Ley Fundamental de 7 de febrero de 1959 retomó la normativa de la Constitución de 1940, realizando cambios menores en la ciudanía y los derechos, y modificaciones sustanciales en la organización de poderes. La

3 Desde el 20 de mayo de 1902 hasta el 1 de enero de 1959, cuatro presidentes no culminaron su mandato, nueve fungieron como gobernantes provisionales y tres fueron derrocados por golpes militares. 
adopción del texto mencionado se amparó en dos razones: su contenido progresista fungía de sostén a las transformaciones que el Gobierno revolucionario se proponía acometer y la promulgación de una nueva carta resultaba inviable en las condiciones políticas en que se desarrollaba el poder revolucionario emergente.

La ley sufrió cientos de reforma mediante un procedimiento expedito en manos del Consejo de Ministros, órgano que concentró el poder legislativo, ejecutivo, gubernativo y constituyente. También fue mutada a través de prácticas políticas, algunas de las cuales se realizaron en concentraciones públicas en las que se adoptaron decisiones o crearon organizaciones. Así, el texto fue multirreformado por vía normativa y convencional, alterándose su fórmula política y rebasándose su techo ideológico, con lo cual, se difuminó como norma suprema y progresó una dilatada provisionalidad estatal de quince años.

El proceso político destituyente/instituyente que comenzó en 1959 tuvo un momento final en los primeros años de la década del setenta con la redacción de 94 leyes sobre diversos ámbitos sociales e institucionales que sentaron las bases para la consolidación del proceso político socialista. En ese tracto, se promulgó la Constitución en 1976, que no se gestó en asamblea constituyente, sino que fue concebida por una comisión, el documento sometido a consulta popular y luego aprobado en referendo ${ }^{4}$.

El texto institucionalizo el socialismo que se edificaba desde 1961 sin refrendo, en particular, siguió el formato de algunas leyes supremas de la antigua Europa del Este (Hungría, Bulgaria, Polonia). De esa manera, se distanció del constitucionalismo nacional y desconoció valiosos antecedentes.

La jerarquía material de la preceptiva se resintió ab initio por varias razones: el texto no postuló su eficacia directa, quedaron contenidos pendientes de leyes complementarias (en 47 ocasiones remitió a leyes de desarrollo), no se concretó un mecanismo de control de constitucionalidad efectivo que propiciara la protección y actualización de la normativa y, en algunos contenidos, se empleó una retórica programática que atentó su juridicidad.

Durante su vigencia, tuvo tres enmiendas formales en 1978, 1992 y 2002. Igualmente, fue mutada, aunque no existen estudios que expongan la magnitud de ese fenómeno. Ocurrieron prácticas políticas que lo complementaron (mutación tácita), se nominalizaron o desactualizaron artículos (mutación por desuetudo) y acaecieron prácticas y se emitieron normas de diferente jerarquía que, obedeciendo al cambio de circunstancias socioeconómicas, contradijeron la

4 En el referendo participó el $98 \%$ de la población mayor de 16 años y se obtuvo el $97,7 \%$ de votos afirmativos. 
preceptiva constitucional (mutación sustancial). En ese caso, la validez de las mutaciones fue controvertible porque, en puridad, se produjo un quebrantamiento de la Ley Fundamental (Dau-Lin, 1988). Durante la década siguiente a su promulgación fungió como referente de la actuación político-jurídica y las relaciones sociales, en la medida que se desactualizó, se redujo a instrumento de ordenación del poder y símbolo del Estado-nación, desvaneciéndose como regla de reconocimiento del ordenamiento jurídico y las relaciones sociales.

La Constitución de 2019 se promulga luego de varios años de ostensible caducidad del texto anterior. No fue concebida en asamblea constituyente como su predecesora, pero, al igual que aquella, el proyecto redactado por una comisión del Parlamento fue sometido a consulta popular ${ }^{5}$ y aprobado mediante referendo ${ }^{6}$. Así, lo que se postuló inicialmente como una reforma al texto de 1976 culminó en una Constitución nueva, cuestión que provocó una ruptura en la continuidad constitucional porque la Asamblea Nacional no tenía competencia para desarrollar una reforma total a partir de la enmienda de 2002.

Como se expone, esta etapa se inicia a partir de una revolución armada que marca un parteaguas en la historia constitucional. La Ley Fundamental de 1959 amparó el proceso de refundación política, pero quedó rebasada por vía normativa y convencional, sobreviniendo un período de inconstitucionalidad y provisionalidad política. El texto de 1976 representó un parteaguas en la historia cubana al legitimar el socialismo y acoger los principios del sistema, en ese punto, ignoró a las constituciones precedente y fue una ley sin muchos aportes técnicos. Su paulatina obsolescencia suscitó anomia constitucional. La Carta Magna de 2009 se distanció del modelo constitucional precedente en varios contenidos, aunque sin abandonar la fórmula política del socialismo, que declara irrevocable en varios momentos, de igual forma, asumió corrientes del constitucionalismo moderno.

\section{EL MODELO DE CONTROL JUDICIAL DE 1901}

En Cuba se puede hablar de control de constitucionalidad a partir del derecho constitucional del siglo xx. La Constitución de 1901, en el art. 83, regulador de las funciones del Tribunal Supremo, refrendó la atribución de

5 Según cifras oficiales, la ciudadanía realizó 1445289 intervenciones, 2100 de ellas procedentes de cubanos residentes en el extranjero, y se incorporaron al proyecto el $40 \%$ de los planteamientos.

6 Acudió a las urnas el 90,15\% de los ciudadanos empadronados y votó positivamente el $78,30 \%$. 
decidir sobre la constitucionalidad de las leyes, decretos y reglamentos cuando fuere objeto de controversia entre partes. La norma fue desarrollada por la Ley de 31 de marzo de 1903, que en el artículo primero reguló que «toda controversia entre partes sobre la constitucionalidad de la Ley, Decreto o Reglamento, será decidida exclusivamente por el Tribunal Supremo de Justicia, en la forma y los trámites que la presente Ley establece» (Borges, 1944: 126). Así, se contornó un procedimiento incidental de parte afectada, que - como reconoció la doctrina de la época - prosperaba cuando se producía «un perjuicio que se corresponda con un derecho cierto, real, del reclamante, trascendente al orden práctico, de carácter privado y de contenido material, en el sentido de que afecte al valor, a la utilidad, económica o de otro orden que el mismo represente» (Blanco, 1941: 117).

Los caracteres de este recurso fueron los siguientes: i) lo interponía la parte perjudicada por una ley, decreto o reglamento que afectara los intereses derivados de un derecho constitucional, causando daño o perjuicio; ii) el juez ordinario en su fallo se abstendrían de pronunciarse sobre ese extremo, dando paso a la acción del interesado; iii) la parte afectada tenía derecho de recurrir al Tribunal Supremo interponiendo recurso de casación o apelación; iv) en caso de procesos que no contaran con los recursos de casación o apelación, el reclamante podía interponer recurso de casación por infracción de ley contra la sentencia dictada en última instancia, y v) la sentencia pronunciada por el Pleno del Tribunal Supremo tenía efecto interpartes, declarativo y ex tunc.

$\mathrm{El}$ artículo octavo de la mencionada ley instituyó también un recurso de inconstitucionalidad administrativo fuera de actuaciones judiciales, que podía ser interpuesto por personas que fueran perjudicadas en actuaciones administrativas. Era una vía directa al margen de una litis. Con posterioridad, el Tribunal Supremo, en las sentencias 23 y 44 de 1935, señaló que la disposición cuya inconstitucionalidad se arguyera debía haber sido aplicada efectivamente.

La Constitución consagró a su vez en el art. 20 una garantía específica para la libertad a través de un recurso que tenía los atributos de habeas corpus, aunque no lo mencionaba como tal, que se interponía por el afectado u otro ciudadano. En el art. 37 reguló una protección normativa para resguardar el contenido esencial de los derechos: «Las leyes que regulen el ejercicio de los derechos que esta Constitución garantiza, serán nulas si los disminuyen, restringen o adulteran» (Lazcano, 1952: 547).

La Ley de 17 de marzo de 1922 en el artículo cuarto, introdujo una innovación por señalar que, al declararse incosntitucional una norma en más de dos ocasiones, la autoridad que la hubiera promulgado debía, en el plazo de 20 días, derogarla o modificarla, transcurrido ese tiempo «[...] la disposición impugnada perderá toda su eficacia y dejara de ser obligatoria en cuanto haya sido declarada contraria a la constitución» (Borges, 1944: 507). Así, se 
adoptó el principio de stare decisis y el fallo del órgano se tornó abrogatorio y erga omnes: "Implicó no solo un cambio notable en cuanto a los efectos de la inconstitucionalidad, sino que de esa forma el expresado recurso había tomado la orientación certera y adecuada de su propia naturaleza, ya que en el fondo de toda acción de inconstitucionalidad se debaten intereses públicos representados por la necesaria intangibilidad del texto constitucional» (Maza, 1944: 139).

La Ley Constitucional del 23 de febrero de 1934 acogió la tipología de control descrito ut supra, pero incluyó en el ámbito de la revisión constitucional a las órdenes y disposiciones emitidas por autoridad o funcionario. Asimismo, al recurso de parte afectada se añadieron dos procedimientos: la acción pública de veinticinco ciudadanos o acción pública plural, y la acción pública de un ciudadano (Ponte, 1958: 350). Estos quedaron expuestos en el art. 78, que señaló que la revisión de constitucionalidad podía ser solicitada a petición de parte afectada o a solicitud suscrita por no menos de veinticinco ciudadanos que estuviesen en pleno goce de sus derechos civiles y políticos. $\mathrm{El}$ art. 38 prescribió también que cualquier acto normativo «que regule el ejercicio de los derechos que esta Ley Constitucional garantiza, serán nulos si los disminuyen, restringen o adulteran. El Tribunal Supremo lo declarará así a petición, en todo tiempo, de cualquier ciudadano en la forma que determina esta Ley Constitucional para los recursos de inconstitucionalidad, sin que puedan volver a aplicarse» (Lazcano, 1952: 625).

La conexión entre los procedimientos citados fue reconocida en la sentencia del Tribunal Supremo número 26 de 29 de septiembre de 1934:

[...] la Ley Constitucional vigente concede tres recursos para impugnar las Leyes, Decretos o actos contrarios a sus disposiciones, uno general utilizable por veinticinco ciudadanos; otro por parte afectada; y otro por cualquier ciudadano cuando sean vulnerados los derechos [...] sin que este último este sujeto a término como lo demuestran las palabras «en todo tiempo» [...] la que solo está subordinada a la forma o requisitos externos de los [otros] dos recursos (Hernández, 1935: 103).

La acción pública colectiva se concibió para la impugnación de normas y disposiciones cuya inconstitucionalidad afectara el interés general, aunque no hubiera creado un perjuicio en su aplicación, lo cual fue reconocido en la Sentencia número 35 de 14 de mayo de 1937:

podía presentarse con independencia de la extensión o pluralidad de los perjuicios privados que haya ocasionado o sea capaz de ocasionar la medida — cuyo ámbito y alcance desde ese punto de vista no se toman en cuenta [...]. Por eso el éxito de la reclamación no se traduce en la reparación del perjuicio sufrido [...] por aquellos a quienes se haya aplicado la ley, no para evitar en lo provenir posibles daños individuales, sino porque cada una de ellas representaría una nueva transgresión a la Constitución (Ponte, 1958: 350). 
Las características del recurso de acción pública plural fueron: i) procedía contra leyes, decretos leyes, decretos, reglamentos, órdenes, disposiciones, acuerdos y actos; ii) debía ser interpuesto por veinticinco ciudadanos acreditados por certificado de nacionalidad o carta de naturalización; iii) los promoventes tenían que estar en pleno goce y ejercicio de sus derechos civiles y políticos; iv) debía ser presentado formalmente por escrito, y v) no prescribía el tiempo para su interposición.

Por su parte, las peculiaridades del recurso de acción pública individual fueron las siguientes: i) procedía contra leyes, decretos, decretos leyes, reglamentos, órdenes y disposiciones; ii) se interponía por un ciudadano; iii) el objeto de demanda era la vulneración de cualquiera de los derechos individuales planteados en la Constitución (la Sentencia número 42 de noviembre de 1934 los restringió a las figuras contenidas en el título IV de la Constitución); iv) la disposición anticonstitucional podía ser previa a la Ley Constitucional (planteado la Sentencia número 26 del Tribunal Supremo); v) debía ser presentado formalmente por escrito en que estuviera consignada la norma que se impugnaba, y vi) el término para su interposición estaba prescrito por ley.

El texto constitucional señaló además tres aspectos aplicables a los recursos citados: i) el tribunal debía proveer un tiempo al demandante para que fueran subsanados los defectos de forma que pudiera tener el recurso; ii) el órgano debía resolver siempre el fondo de reclamación, y iii) una vez declarada la inconstitucionalidad no podría aplicarse nuevamente en ninguna forma ni con ningún pretexto (fue ratificado por la Sentencia número $41 \mathrm{de}$ febrero de 1939), por lo que el fallo adquiría alcance constitutivo, ex nunc, y erga omnes.

La jurisdicción de la libertad quedó reforzada con el procedimiento de habeas corpus que se refrendó en el art. 21 constitucional, el que se desarrollaba ante los tribunales ordinarios cuando alguna persona fuera detenida o presa sin las formalidades legales, o fuera de los casos previstos en la Constitución y las leyes. El precepto incorporaba también la responsabilidad en que incurría el funcionario responsable, que sería detenido como infractor y juzgado como reo de un delito de desobediencia grave.

Como se comenta, iniciando el siglo xx se instauró en Cuba un tipo de control constitucional en manos del máximo órgano del Poder Judicial con tres vías procesales fundamentales: el recurso incidental de parte afectada, la acción pública plural y la acción pública individual, que permitían un control

La sentencia recibió el voto particular de los magistrados Gastón Mora y José F. Perera, que se opusieron a la visión restringida y sostuvieron que debía abarcar a todos los derechos del ciudadano establecidos en cualquier precepto constitucional, o derivados del principio de soberanía y la forma de gobierno. 
abstracto. Las dos últimas acciones, implementadas en los años treinta, junto con la adopción del principio del stare decisis que dotaba a la decisión de efectos erga omnes, conformaron un modelo avanzado para la región.

Para contextualizar lo que se afirma, debe considerarse que en América Latina el primer constitucionalismo de inicios del siglo XIX asumió la tipología de control político bajo el influjo francés y español, el que depositaron, primordialmente, en una Cámara del Congreso o el Consejo de Estado. Posteriormente, durante la segunda mitad de la centuria, la mayoría de los países adoptó el judicial review, pero con diferencias respecto al prototipo norteamericano. Un elemento que lo diferenció fue que el órgano supremo del poder judicial monopolizó la función, no permitiéndosele a los jueces de instancia desaplicar normas inconstitucionales; por ello, García Belaunde ha planteado con acierto que en realidad se constituyó un tipo de control concentrado, pero en manos del poder judicial (García Belaunde, 2014: 304). Otra novedad fue que se instrumentaron vías procesales directas para demandar la inconstitucionalidad; verbi gratia, la acción popular refrendada primigeniamente por la Constitución de Cundinamarca de 1811, y el amparo regulado por la Constitución de Yucatán de 1841, y luego generalizado a todo México por el Acta Constitutiva y de Reformas de 1847.

Cuba, que inició su camino como nación independiente con un siglo de diferencia en relación con Latinoamérica, adoptaba la tendencia predominante en el área en su versión más acabada.

\section{EL TRIBUNAL DE GARANTÍAS CONSTITUCIONALES Y SOCIALES DE 1940}

La Constitución de 1940 y la Ley 7 de 31 de mayo de 1949, que desarrolló la institución, introdujeron novedades en el canon de justicia constitucional. La primera y más descollante fue la creación del Tribunal de Garantías Constitucionales y Sociales como sala especializada del Tribunal Supremo. A su vez, se ampliaron las vías procesales para el reclamo de la inconstitucionalidad de normas, disposiciones y actuaciones. También, se enfatizó el principio de supremacía constitucional como parámetro de interpretación en el art. 194: «Los jueces y tribunales están obligados a resolver los conflictos entre las leyes vigentes y la Constitución, ajustándose al principio de que ésta prevalezca siempre sobre aquélla» (Lazcano, 1952: 847).

El TGCS quedó integrado por nueve magistrados, uno de los cuales fungía como presidente; además, un abogado fiscal y un abogado de oficio. Los jueces eran nombrados por el presidente de la República, de una terna que proponía un colegio electoral designado por el Pleno del Tribunal Supremo, 
el titular del Ejecutivo y la Facultad de Derecho de la Universidad de La Habana. La sala era presidida por el presidente del Tribunal Supremo en los asuntos constitucionales, ampliándose la composición a quince miembros (se incorporaban los presidentes de las demás salas).

Los arts. 174 y 182 de la Constitución estipulaban el carácter bifronte del órgano: «[...] decidir sobre la constitucionalidad de las leyes, decretosleyes, decretos, reglamentos, acuerdos, órdenes, disposiciones y otros actos de cualquier organismo, autoridad o funcionario, y conocer de las cuestiones jurídico-políticas y las de legislación social que se sometan a su consideración». En esos ámbitos, podía ir contra la actuación de cualquier poder o agente del Estado, siendo sus resoluciones inapelables. Ello lo contornaba como un órgano omnipotente, en tanto devenía en tribunal constitucional, de casación, de consultas, de apelación y de garantía de la libertad. Ello fue criticado por la doctrina de la época al señalar que suponía una invasión del poder jurisdiccional en el legislativo y un desequilibrio entre las competencias respectivas de los poderes (Blanco, 1941: 118).

Las competencias del órgano eran desarrolladas in extensus por la ley orgánica. Una valoración de estas revela las diferentes dimensiones de su actuar.

- Órgano revisor de la constitucionalidad de las normas: conocía el recurso de inconstitucionalidad contra normas, disposición, resolución judicial o acto; el recurso de queja contra actuaciones que entorpecieran la acción privada de inconstitucionalidad fuera del litigio entre partes, y evacuaba las consultas de los jueces sobre constitucionalidad de normas.

- Órgano verificador de la constitucionalidad de la actuación de los poderes públicos: ventilaba el recurso contra los abusos de poder y revisaba la validez de los procesos de reforma de la Constitución.

- Jurisdicción constitucional orgánica: conocía el recurso de inconstitucionalidad contra todo tipo de norma o actuación que impidiera el funcionamiento adecuado de un órgano del Estado y el recurso contra las sentencias que juzgaran al presidente de la República, los ministros, los gobernadores y los magistrados del Tribunal Supremo.

- Jurisdicción de la libertad: tramitaba el recurso de inconstitucionalidad contra toda norma, disposición o acto que disminuyera, restringiera o adulterase derechos; el recurso de inconstitucionalidad contra la expropiación a la propiedad en caso de falta de certeza de la utilidad de este acto; el recurso de apelación de habeas corpus, y el recurso de inconstitucionalidad en que se impugnara la retroactividad de una ley.

- Sala social: gestionaba los recursos de apelación y casación que autorizaran las leyes para desarrollar los derechos económicos; los recursos que versaran sobre derechos y obligaciones de carácter social, las relaciones entre patro- 
nos y obreros o que afectaran el derecho de estos y los recursos contra las resoluciones de las comisiones de conciliación o tribunales del trabajo.

- Evaluaba las consultas de los jueces sobre la constitucionalidad de las normas que se aplicarían en un juicio y que se consideraba que violaban derechos o garantías previstos en la constitución.

En los anteriores ámbitos se regulaba una variedad de recursos. Los más importantes eran los siguientes.

- Recurso de inconstitucionalidad promovido por acción privada dentro de actuación judicial, cuando en el marco de una litis una de las partes alega la inconstitucionalidad de una norma, disposición, acuerdo, medida o acto. Sus requisitos fundamentales eran a) que el demandante expusiera la afectación o interés lesionado y el artículo de la constitución violado o indebidamente aplicado; b) ser interpuesto directamente ante el TGCS, y c) plazo de diez días si el demandante era residente en las provincias occidentales, o quince si era de las orientales.

- Recurso promovido por acción privada fuera de actuación judicial cuando se aplica una norma, disposición, acuerdo, medida o acto inconstitucional a una persona. Sus requisitos fundamentales eran a) que el demandante diera a conocer por escrito al funcionario o autoridad responsable su propósito de interponer el recurso de inconstitucionalidad; b) plazo de cinco días siguientes a la notificación de la disposición perjudicial; c) exhibir la solicitud en que pide copia de la orden o resolución lesiva; d) que la resolución $\mathrm{u}$ orden que reclamaba fuera firme; e) representación letrada; f) exponer los hechos, fundamentar la inconstitucionalidad y mencionar el artículo constitucional vulnerado; g) entregar tantas copias como partes eran emplazadas, y h) plazo de diez o quince días, en dependencia de la residencia del postulante.

- Recurso promovido por acción pública de veinticinco ciudadanos contra disposiciones de carácter general (norma, medida, acto o acuerdo) que atentara contra la vigencia de algún precepto constitucional. Su intención no era la reparación de un perjuicio sino la salvaguarda del orden constitucional. Sus requisitos fundamentales eran a) que los promoventes acreditaran su condición de ciudadanos y estuvieran en pleno goce de sus derechos; b) representación letrada; c) consignación de la fecha de la disposición impugnada, el fundamento de inconstitucionalidad de esta y el artículo constitucional que infringía, y d) plazo de un año desde la promulgación de la norma.

- Recurso promovido por acción pública contra disposiciones o actos generales que negaran, disminuyan, restrinjan o adulteren derechos y 
garantías, o que impidan el libre funcionamiento de los órganos del Estado. Sus requisitos fundamentales eran: a) podía ser promovido por una amplia gama de sujetos: el presidente, los miembros del Consejo de Gobierno, senadores, diputados, miembros del Tribunal de Cuentas, gobernadores, alcaldes, concejales, jueces, tribunales, el Ministerio Fiscal, las universidades, los organismos autónomos autorizados, persona individual o colectiva que haya sido afectada por un acto o disposición que considere inconstitucional, $\mathrm{u}$ otros siempre que presten la fianza correspondiente; b) que los promoventes debían tener plena capacidad civil; c) representación letrada, y d) prestación de fianza.

- Recurso promovido por acción pública de veinticinco ciudadanos o uno o varios miembros de alguna de las Cámaras del Congreso contra acuerdos que infrinjan los preceptos que regulan las relaciones entre ambos cuerpos colegisladores, afecten el proceso de formación de las leyes, o vicien formalmente una ley durante su creación. Sus requisitos fundamentales eran a) que fuera interpuesta en el transcurso de un año desde la afectación, y b) exhibición de los fundamentos.

- Recurso por acción pública promovido por veinticinco ciudadanos, una o varias personas o el Ministerio Fiscal, contra las infracciones del procedimiento de reforma constitucional estipulado en la constitución, los acuerdos de la asamblea plebiscitaria o el Congreso que apruebe la reforma. La demanda debía ser interpuesta en el término de treinta días desde la fecha de publicación de la ley que disponía la convocatoria de referendo o la elección de los delegados a la constituyente, o de noventa desde que se declarara la validez de la reforma.

- Recurso contra el abuso de poder que realice cualquier órgano de poder. Era un proceso para uso de los organismos públicos a fin de proteger sus facultades y régimen de autonomía de las extralimitaciones que podían tener otros órganos estatales superiores. La demanda debía ser interpuesta en el término de ciento ochenta días desde la fecha de la promulgación de la resolución recurrida.

- Recurso de habeas corpus por vía de apelación ${ }^{8}$ contra la resolución dictada por un tribunal ordinario o en caso de que no se hubiera hecho

8 Existía un procedimiento sumarísimo de habeas corpus en vía ordinaria regulado por el art. 29 constitucional para todo aquel que se encontrara detenido o preso fuera de los casos previstos o sin las formalidades estipuladas. Este recurso declaraba nula de oficio cualquier disposición que impidiera o retardara la presentación de la persona privada de libertad. "Cuando el detenido o preso no fuere presentado ante el Tribunal que conozca del habeas corpus, éste decretará la detención del infractor, el que será 
eficaz la resolución de habeas corpus. La demanda debía ser interpuesta por la persona que hubiera sido parte en el procedimiento, u otra que actuara en su nombre en caso de que se encontrara impedida.

- Recurso de apelación contra las resoluciones del Tribunal Superior Electoral que violen preceptos constitucionales en el caso de candidatos a presidente, vicepresidente, senador y gobernador que hubieran sido declarados no electos por sentencia de ese órgano.

- Recurso de apelación o casación en materia de derechos económicos contra las resoluciones del Ministerio de Trabajo en materia de controversia laboral, despido obrero, descanso retribuido, excedencias, escalafones, sindicación, contratos de trabajo, salarios, jornada de trabajo, maternidad obrera, condiciones de trabajo, relaciones entre patrones y obreros $\mathrm{u}$ otros que afecten derechos de los patrones o de los trabajadores. También contra los acuerdos de los directorios de retiro o seguro social que versen sobre jubilaciones, pensiones y retiros de determinados sectores profesionales y obreros. Igualmente, contra las resoluciones de las comisiones de conciliación o de los tribunales de trabajo. Sus requisitos fundamentales eran a) término de diez días luego de haber sido notificada la resolución lesiva, y b) exponer los motivos de hecho y de derecho.

La tutela de los derechos se reforzaba por una protección al contenido esencial en el art. 40 constitucional, más abarcadora que la comentada anteriormente: «Las disposiciones legales, gubernativas o de cualquier otro orden que regulen el ejercicio de los derechos que esta Constitución garantiza, serán nulas si los disminuyen, restringen o adulteran» (Lazcano, 1952: 847).

Los recursos de inconstitucionalidad podían ser motivados por vicio material (inconstitucionalidad intrínseca) o por defecto de forma (inconstitucionalidad extrínseca). En el primer caso las normas eran impugnadas, aunque se hubiesen promulgado antes de la entrada en vigor de la Constitución.

Respecto al escrito de presentación, en el art. 194 constitucional se planteaba que si adoleciere de algún defecto de forma, (los tribunales) concederán un plazo al recurrente para que lo subsane, y añadía que los tribunales debían resolver siempre el fondo de la reclamación.

Las formalidades de las demandas fueron precisadas por la jurisprudencia al reconocer como defectos que invalidaban la presentación de los recursos

juzgado de acuerdo con lo que disponga la Ley. Los Jueces o Magistrados que se negaren a admitir la solicitud de mandamiento de habeas corpus, o no cumplieren las demás disposiciones de este Artículo, serán separados de sus respectivos cargos por la Sala de Gobierno del Tribunal Supremo». 
los siguientes: i) establecer la acción en una vía improcedente; ii) ejercitarlo fuera del término; iii) anunciarlo indebidamente ante quien no procedía; iv) no acompañar las pruebas pertinentes, y v) ejercer la acción después de haber aceptado la aplicación del precepto tachado de inconstitucional (Garcerán, 1947: 37; de Montagú, 1951: 27).

Las decisiones sobre inconstitucionalidad se adoptaban por mayoría absoluta de votos. Si ese porcentaje cualificado no se obtenía, la ley orgánica estipulaba la realización de una segunda votación a fin de lograr una posición inequívoca al respecto.

Podían iniciar la declaración de inconstitucionalidad los interesados en los juicios, causas o negocios de que conociesen la jurisdicción ordinaria y las especiales, veinticinco ciudadanos que justificasen su condición de tales, y la persona a quien afectase la disposición que estimase inconstitucional. Se añadían otros sujetos que podían acudir al tribunal en determinados recursos públicos: presidente de la República, miembros del Consejo de Gobierno, representantes y senadores, integrantes del Tribunal de Cuentas, gobernadores, alcaldes, concejales, jueces, el Ministerio Fiscal, las universidades, los organismos autónomos autorizados por la Constitución y toda persona individual o colectiva que hubiera sido afectada por un acto o disposición que considerase inconstitucional.

En sintonía con la tendencia que se había introducido desde 1922, el efecto de la sentencia declarativa de inconstitucionalidad rebasaba a las partes, ya que la norma o acto impugnado no podría emplearse nuevamente. El art. 194 constitucional señalaba que el organismo, autoridad o funcionario que hubieren dictado la disposición anulada estaba obligado a derogarla de inmediato. Los arts. 73 y 74 de la Ley 7 planteaban que la disposición o medida se consideraría nula y sin valor ni efecto desde el día de la publicación de la sentencia, adquiriendo el fallo adquiría efectos constitutivos, en nunc y erga omnes.

La mencionada ley agregaba en el art. 74 que, si la declaración de inconstitucionalidad era por defecto de forma, el fallo, a discreción del tribunal, podía adquirir efectos generales retroactivos. El art. 75 contemplaba otras variantes en las que la sentencia adquiría efectos ex tunc: aplicación indebida de retroactividad de una ley no penal, expropiación de bienes con incumplimiento de los requisitos previstos en la constitución, disposición legal o gubernativa restrictiva de derechos, disposiciones modificativas de la legislación electoral, etc.

Como se evidencia, se contornó un modelo de control concentrado, semiespecializado, abarcador; desarrollando por acción y de manera principal, a la par que, por excepción y de forma incidental. Así se desplegó un tipo de control, promovido por interés directo, y a su vez abstracto, no vinculado con 
agravios. La sentencia tenía efecto erga omnes, constitutivo y ex nucn, pero podía adquirir también efectos ex tunc en determinados casos. Con estos caracteres orgánico-funcionales, el canon implementado en 1940 se desmarcó del modelo de la carta de 1901, y paralelamente, del prototipo estadounidense. Se siguió el paradigma europeo

Para comprender la génesis de este arquetipo, debe tenerse presente que el proceso de expansión de los mecanismos de justicia constitucional que comenzó en los inicios del siglo xx provocó en las siguientes décadas que se configuraran arquetipos en los que se desdibujaron los rasgos antitéticos de los modelos concentrado y difuso. Como afirma Fernández Segado, se produjo un movimiento de avecindamiento entre los dos sistemas, una atenuación de las claras contraposiciones ideológicas que están en la base de aquellas (Fernández, 2004: 91). Verbi gratia, países del sistema difuso institucionalizaron salas constitucionales en la corte suprema propiciando una especialización de la función; asimismo, la máxima magistratura redujo los casos que conocía a tenor del principio de writ of certiorari y la sentencia adquirió eficacia erga omnes por la aplicación del principio de stare decisis. Por su parte, en países del tipo concentrado, los tribunales ordinarios se sumaron a la tarea de depuración del ordenamiento jurídico mediante la cuestión de inconstitucionalidad, posibilitando que los jueces de instancia realizaran un primer test de constitucionalidad; también, se refrendaron recursos que protegían a los derechos fundamentales en los tribunales ordinarios.

En esa línea hay que inscribir el Tribunal de Garantías Constitucionales y Sociales que introdujo la Constitución de 1940. Cuatro décadas después, esta variante fue seguida por otros países del área: en 1983 se creó en El Salvador la sala constitucional dentro de la Suprema Corte a tenor de la Constitución promulgada en ese año; en 1995 sucedió en Nicaragua mediante una reforma constitucional; en 1989 la introdujo Costa Rica de igual manera; en 1992 Paraguay adoptó la sala especializada en la Constitución de ese año; en 1999 la instituyó Venezuela mediante la Carta Magna de igual fecha, y en el año 2000 la refrendó Honduras por una reforma constitucional.

Por la fecha en que se instituía la sala especializada cubana, la Constitución de Ecuador de 1945 introducía el Tribunal de Garantías Constitucionales como órgano autónomo, aunque este tuvo una eficacia limitada por su composición no especializada y el hecho de que solo podía suspender provisionalmente la vigencia de una ley inconstitucional hasta que el Congreso adoptara la decisión final; además, solo funcionó durante un año. Fue reinstaurado en 1998 como Tribunal Constitucional y la Carta Magna de 2008 lo ratificó como Corte Constitucional.

Años después, varios países adoptaron órganos ad hoc para el ejercicio de la función: en 1965 la Constitución de Guatemala instituyó la Corte Consti- 
tucional, que funcionó hasta 1982, en que se produjo el golpe de Estado, retomándose en 1985; en 1971 se creó el Tribunal Constitucional en Chile a tenor de una reforma de la Constitución; en 1979 surgió el Tribunal de Garantías Constitucionales de Perú en la Ley Fundamental de ese año, denominándose Tribunal Constitucional en 1993; en 1991 se instituyó la Corte Constitucional de Colombia mediante la Carta Magna de igual fecha, y en 1994 se creó el Tribunal Constitucional de Bolivia por una reforma constitucional que se convirtió posteriormente en el Tribunal Constitucional Plurinacional en 2009.

Se ha debatido cómo podría clasificarse el TGCS cubano. El mencionado Fernández Segado consideró que fue un embrión de tribunal constitucional: «[...] puede ser considerado como la primera experiencia iberoamericana que, muy tempranamente reflejará, parcial, impropia o desnaturalizadamente si se prefiere, el modelo europeo, [así] se puede valorar la trascendencia del paso dado por los constituyentes cubanos» (Fernández Segado, 2014: 205). El también citado García Belaunde señaló que fue un planteamiento original, que constituyó el "primer y más elaborado esbozo de modelo concentrado en América Latina» (Belaunde, 2014: 238). En la doctrina nacional, Ramón Infiesta señaló que con la creación del tribunal se estructuró un modelo de control mixto porque si bien se incardinaba en el Tribunal Supremo «por la competencia y en el procedimiento, era un verdadero Tribunal separado" (Infiesta, 1942: 112). Este criterio siguieron otros investigadores cubanos (Méndez y Cutie, 2009: 513; Fernández, 1994: 19).

A favor de la idea de que se configuró un órgano al estilo europeo puede aducirse, además de la denominación y el tratamiento normativo especial, lo siguiente: la sala/tribunal concentraba el control constitucional, no se subordinaba a ninguna institución y sus fallos tenían efectos erga omnes. En defensa de la tesis de que no se conformó una corte constitucional puede argüirse que el órgano no poseía autonomía funcional, los jueces tenían el mismo estatus que el resto de los magistrados, para resolver los temas de inconstitucionalidad debía adoptar una composición ampliada y encabezarlo el presidente del Tribunal Supremo y sus atribuciones rebasaban el contenido meramente constitucional.

Es evidente que los constituyentistas de 1940 se propusieron construir un prototipo que se desmarcara del judicial review plus instaurado en 1901. Así, denominaron al órgano como tribunal y lo dotaron de una norma particular (sección tercera del capítulo XIV dedicado al Poder Judicial en la Constitución y Ley 7/1949); empero, el atrevimiento no llegó hasta concebirlo como un ente autónomo. El órgano, la cantidad de acciones procesales que se refrendaron y los efectos de estas contornaron un canon revolucionario en la región. En esta ocasión, no se siguió la tendencia sino que se marcaba pauta. 


\section{EL CONTROL POLÍTICO INSTITUIDO EN 1976 Y EL NUEVO CANON DE 2019}

La Ley Fundamental de 1959 mantuvo el TGCS, pero una ley de reforma de 1960 cambió la denominación del órgano por el de sala, remarcando su integración en el Tribunal Supremo. Aunque el órgano pervivió, su actividad languideció por autoinhibición política y el desuetudo de la Ley Fundamental. En 1973 se promulgó la Ley 1250 de Organización del Sistema Judicial, que reorganizó la judicatura y lo extinguió.

La Constitución de 1976 que institucionalizó el sistema socialista mutó las coordenadas de la justicia constitucional al adoptar una tipología de control constitucional político. En el nuevo entramado de órganos supremos que se instauró, la Asamblea Nacional de Poder Popular, órgano supremo del poder del Estado con función constituyente y legislativa, tenía entre sus atribuciones la revisión de la constitucionalidad de las normas y disposiciones. Ello se encontraba en la tendencia que abrazó el constitucionalismo socialista europeo.

El Reglamento de la Asamblea Nacional de 18 de julio de 1977, en los arts. del 93 al 98, reguló el proceso de revisión de constitucionalidad de las normas y otras disposiciones por causas formales y materiales. Los sujetos legitimados eran los diputados, el Consejo de Estado, el Comité Ejecutivo del Consejo de Ministros, las Asambleas municipales y provinciales del Poder Popular, el Tribunal Supremo Popular y la Fiscalía General. También se reconoció una acción pública de veinticinco ciudadanos que se hallaren en pleno goce de sus derechos.

El escrito que iniciaba el proceso tenía que identificar la disposición o norma que se impugnaba, el órgano emisor y la razón de inconstitucionalidad; se presentaba al presidente de la Asamblea Nacional, quien lo remitía a la comisión de asuntos constitucionales y jurídicos para que dictaminara. El órgano legislativo debía pronunciarse en los siguientes términos: negar la solicitud por improcedente, revocar la norma o derogarla parcialmente.

El 5 de agosto de 1982 la ANPP promulgó un nuevo reglamento, que ratificó lo estipulado en la norma anterior, incorporando al Consejo de Ministros entre los sujetos legitimados para solicitar la revisión de constitucionalidad.

El 25 de diciembre de 1996 se emitió otro reglamento, que excluyó el procedimiento de control descrito. Al paralelo, la Asamblea Nacional promulgó el Acuerdo IV-57, que encomendaba redactar un proyecto de ley sobre el tema, propuesta que nunca se concretó. De esa forma, desapareció la vía imprecisa y limitada de control político descrita, instaurada en contrasentido al mecanismo de justicia constitucional que había evolucionado durante décadas en el país y constituyó un referente regional. 
Como se constata, el texto constitucional de 1976 soslayó los dos antecedentes que se habían adoptado en el constitucionalismo nacional (modelo concentrado y no especializado en manos del Tribunal Supremo/modelo concentrado y semiespecializado en el Tribunal de Garantías Constitucionales y Sociales), instituyendo un esquema de control político que, por demás, no terminó de configurar jurídicamente. Fue la tendencia de la doctrina socialista europea, con excepción de Yugoslavia y Checoslovaquia, que en las constituciones 1963 y 1968, respectivamente, implementaron tribunales constitucionales. Esta postura fue correlato de la concepción político-formal de constitución que sostuvo el socialismo y el principio de unidad de poder que concebía a las Asambleas nacionales como el órgano supremo del poder soberano.

El nuevo texto constitucional de 2009 supera la exclusión que tuvo el documento del 76 respecto al tema en análisis, lo que es loable. Lo primero a destacar es que refrenda el principio de supremacía constitucional y asienta una cláusula de protección genérica al referir que «todos están obligados a cumplirla»; añadiendo que las disposiciones y actos del Estado, sus funcionarios y organizaciones se ajustan a sus presupuestos?

En el capítulo sexto, regula dos garantías específicas de las libertades, o, en estricto sensu, reconoce una que ya existe en el ordenamiento jurídico y delinea otra. Refrenda el habeas corpus como garantía de la libertad, institución que se encontraba olvidada en el art. 467 y siguientes de la Ley de Procedimientos Penales de 13 de agosto de 1977; y en el art. 92 esboza la vía procesal de garantía de los derechos, al afirmar que «las personas pueden acceder a los órganos judiciales a fin de obtener una tutela efectiva de sus derechos e intereses legítimos».

La configuración de ambos procesos queda en manos de legislador, cuando por su importancia debió delimitarlos el constituyente. El silencio es particularmente trascendente en la acción de tutela porque se introduce en un entorno en el que no existe cultura de garantías procesales a los derechos, la institución no tiene referente inmediato y en Cuba tampoco existe tradición de control difuso. Por tanto, el mutismo del constituyente plantea una infinidad de preguntas sobre los contornos básicos de la institución que debían estar en la Ley Fundamental.

Más adelante, la Constitución plantea que la persona a la que se le vulneren los derechos y sufriere daño o perjuicio por acción u omisión tiene derecho a reclamar ante los tribunales la restitución del derecho y la reparación o indemnización mediante un procedimiento preferente, expedito y concentrado; agregando al final del artículo que la «ley establece aquellos derechos

9 Constitución de 2019. Disponible en: https://bit.ly/2AtxLoW. 
amparados por esta garantía». La redacción suscita dudas: ¿̨la sentencia del proceso de tutela no entraña la restitución y reparación?, ¿se refiere a otro proceso?, ¿no todos los derechos vulnerados serían restituidos y reparados?

El capítulo introduce también en el art. 97 el derecho de acceso a la información de datos personales que se encuentra en registros públicos, unificando en un precepto el derecho a conocer los datos que se encuentran almacenados, la posibilidad de actualizarlos, rectificarlos o suprimirlos y la facultad de exigir su protección. En el derecho comparado, existen constituciones que refrendan el derecho (acceso a la información) y la acción procesal (habeas data) al unísono, mientras otras lo hacen por separado; empero, en cualquier caso, queda claro que constituyen cuestiones diferentes.

El precepto que comentamos lo enuncia como derecho, aunque la inclusión en el capítulo presupone que de este se deriva una garantía, sentido en el que la formulación es omisa.

Por otro lado, en los ordenamientos jurídicos comparados el derecho se ejercita frente a las entidades públicas y privadas, sin embargo, el texto cubano menciona «registros, archivos u otras bases de datos e información de carácter público", lo cual estampa una interrogante no poco importante: ¿quién determina el carácter público o no de un dato personal? El cambio puede resultar significativo para la efectividad del derecho en el entorno de una administración pública con vicios burocráticos y con síndrome de secretividad.

La garantía orgánica de la Constitución queda encomendada, ex novo, a la Asamblea Nacional del Poder Popular en el art. 158 inciso e): «[...] ejercerá el control de constitucionalidad sobre las leyes, decretos-leyes, decretos presidenciales, decretos y demás disposiciones generales»; procedimiento que, igualmente, se encarga al legislador. Así, se continúa apostando por el control político que ninguna eficacia ha tenido en el derecho constitucional.

Por otra parte, el artículo no especifica si el control es previo o posterior. $\mathrm{Si}$ es previo, no es verdadero control, sino revisión de constitucionalidad del proyecto de norma. Si es a posteriori asalta la pregunta: ¿la ANPP revisora de la constitucionalidad actuará contra la ANPP legisladora?

La Carta Magna de 2019 sobrepasa el anterior texto, pero no diagrama de manera completa un modelo de control de constitucionalidad. Establece la garantía de los derechos en sede judicial y la revisión de la constitucionalidad de las leyes en el órgano legislativo-constituyente, a pesar de lo evidente de la inoperancia de esta tipología; además, todo queda pendiente de configuración legislativa. La propuesta es incompleta, inconexa, timorata, en contrasentido a la tendencia mundial, y no asegura adecuadamente el derecho ciudadano a la supremacía de la Constitución.

¿Cuál hubiera sido una propuesta ideal a tono con la nueva Constitución que introdujo cambios significativos? Considero que un modelo mixto, 
como el instaurado en numerosos países de América Latina, algunos de ellos con notoria estabilidad y eficacia, e importante jurisprudencia. Una propuesta pertinente a mi juicio podría haber sido retomar la sala constitucional dentro de la máxima magistratura, y en paralelo, reconocer a los jueces facultades de revisión de constitucionalidad en los casos que ventilan. La sala constitucional tendría funciones de control previo (dictaminaría sobre la constitucionalidad de proyectos legislativos y tratados internacionales; la ejecución de referendos y consultas populares, y las preguntas que en estos se realizaran; revisaría la legitimidad de la reforma parcial de la constitución; resolvería consultas del Ejecutivo, etc.) y a posteriori (conocería el recurso de inconstitucionalidad de carácter abstracto por vía de acción directa, la demanda de constitucionalidad de carácter concreto, la acción de cumplimiento de sentencias, y atraería en revisión determinados casos de tutela de derechos a fin de homogenizar jurisprudencia). Por su parte, los tribunales provinciales sustanciarían el proceso de tutela de derechos, $\mathrm{y}$ todos los jueces tendrían competencia para desaplicar normas y decisiones inconstitucionales en casos concretos.

\section{Bibliografía}

Alonso Romero, M. P. (2002). Cuba en la España liberal (1837-1898). Génesis y desarrollo del régimen autonómico. Madrid: Centro de Estudios Políticos y Constitucionales.

Álvarez Tabío, F. (1953). Evolución constitucional de Cuba (1928-1940). La Habana: Talleres Gráficos O'Reilly.

Bizcarrondo, M. y Elorza, A. (2001). Cuba/España. El dilema autonomista, 18781898. Madrid: Editorial Colibrí.

Blanco, A. (1941). Sobre la técnica del Tribunal Supremo en materia inconstitucional. Revista Cubana de Derecho, año XV, 1 (57), 117-123.

Borges, M. A. (1944). Compilación ordenada y completa de la Legislación cubana de 1899 a 1950 (vol. 1). La Habana: Editorial Lex.

Dau-Lin, H. (1988). Mutación de la Constitución. Oñate/Onati: Instituto Vasco de Administración Pública/Herri Arduralaritzaren Euskal Erakundea.

De Montagú, G. (1951). El poder judicial y la Constitución y otros estudios. La Habana: Culturas S. A.

Fernández Bulté, J. (1994). Los modelos de control de constitucionalidad y la perspectiva de Cuba de hoy. Revista El Otro Derecho, 6 (2), 19-31.

Fernández Segado, F. (2004). La justicia constitucional en el siglo XXI: la progresiva convergencia de los sistemas americano y europeo-kelseniano. México: Instituto de Investigaciones Jurídicas; Universidad Nacional Autónoma de México. 
Ferrara, O. (1945). Las ideas jurídico-sociales en las constituciones cubanas. Conferencia pronunciada en el ilustre Colegio de Abogados de Madrid el 29 de enero de 1945. Madrid: Talleres Gráficos Marsiega.

Franco Pérez, A. F. (2002). Cuba y el orden jurídico español del siglo xix: la descentralización colonial como estrategia y táctica jurídico-política (1837-1898). Revista de Historia Constitucional, 5, 313-324.

Garcerán, J. (1947). Estudio crítico del recurso de inconstitucionalidad. Su fundamento, origen y desenvolvimiento. En Anuario de la Asociación Nacional de Funcionarios del Poder Judicial. La Habana: Editorial LEX.

García Belaunde, D. (2014). El Tribunal de Garantías Constitucionales y Sociales de Cuba (1940-1952). Boletín Mexicano de Derecho Comparado, 37 (109), 238-312.

Gutiérrez y Sánchez, G. (1938). Historia del Derecho Constitucional cubano. La Habana: Cultura S. A.

Hernández Corujo, E. (1935). La acción pública en materia de inconstitucionalidad en Cuba. La Habana: Imprenta y Papelería de Rambla, Bouza y Ca.

— (1960). Historia constitucional de Cuba (vol. 1). La Habana: Compañía Editora de Libros y Folletos.

Infiesta y Pages, R. (1942). Derecho Constitucional. La Habana: Editorial Selecta.

Lazcano y Mazón, A. M. (1952). Las Constituciones de Cuba. Madrid: Ediciones Cultura Hispánica.

Maza, E. (I944). El recurso de inconstitucionalidad. Sus fuentes actuales. Revista Cubana de Derecho, 2 (70), 139-151.

Méndez López, J. y Cutie Mustelier, D. (2009). La función de los tribunales de salvaguardar la Constitución. En A. Matilla Correa (comp.). Estudios cubanos sobre control de constitucionalidad (1901-2008) (pp. 487-536). México: Editorial Porrúa.

Ponte, F. J. (1958). Historia de la Guerra de los 10 Años. La Habana: Imprenta El Siglo XX; Muñiz y Cía.

Portuondo Zuñiga, O. (2008). Cuba. Constitución y liberalismo (1808-1841) (vol. 2). Santiago de Cuba: Editorial Oriente.

Roig de Leuchsenring, E. (1961). Historia de la Enmienda Platt. La Habana: Instituto Cubano del Libro.

Suárez Suárez, R. (2011). Repercusiones de la Constitución de Cádiz en Cuba (18121814). En C. Villabella Armengol. Hitos constitucionales del siglo XIX cubano. Camagüey: Editorial Ácana.

Varela Suanzes-Carpegna, J. (1983-1984). La Constitución española de 1837: una constitución transaccional. Revista de Derecho Político, 20, 95-106.

- (20II). La construcción del Estado en la España del siglo XIX. Una perspectiva constitucional. En C. Villabella Armengol. Hitos del constitucionalismo del siglo XIX cubano. Camagüey: Editorial Ácana.

Villabella Armengol, C. M. y Matilla Correa, A. (2009). Guáimaro: alborada en la historia constitucional cubana. Camagüey: Ediciones Universidad.

Vitier, C. (1990). Ese sol del mundo moral. La Habana: Ediciones Unión. 